\title{
Comparison of PO and INC MPPT Methods Using FPGA In-The-Loop under Different Radiation Conditions
}

\author{
Reşat Çelikel and Ahmet Gündoğdu
}

\begin{abstract}
In photovoltaic (PV) systems, the Maximum Power Point Tracking (MPPT) algorithms are applied to obtain maximum efficiency under different atmospheric conditions. Among the MPPT methods, Perturb \& Observe (PO) and Incremental Conductance (INC) methods are the oldest algorithms that have been used. Field Programmable Gate Arrays (FPGA) are used especially in applications requiring high speed. FPGA in-the-loop feature is used to test algorithms designed in MATLAB/Simulink environment. In this study, PO and INC methods were designed to work in FPGA environment. Both algorithms were tested under different radiation conditions by using FPGA-in-the-loop feature. The FPGA in-the-loop simulation result of $\mathrm{PO}$ and INC methods was shown graphically. Altera DE2-115 development board was used to test PO and INC MPPT algorithms. In addition, PO and INC methods were synthesized using the Quartus-II program. Comparisons of the simplicity of the algorithms were made based on the synthesis results. Thus, by using the FGPA in-the-loop feature and performing the synthesis process, both of the algorithms were tested and the areas covered by the algorithms in the FPGA were compared.
\end{abstract}

Index Terms-Solar Energy, PV systems, MPPT Algorithms, FPGA, Perturb and Observe, Incremental Conductance, Photovoltaic Energy Conversion.

\section{INTRODUCTION}

COLAR ENERGY is used extensively in renewable energy $N_{\text {systems. However, due to the low efficiency of }}$ photovoltaic (PV) systems, various algorithms have been developed to obtain maximum energy from PV modules [1-2]. Among these algorithms, the oldest and most heavily used

REŞAT ÇELIKEL, is with Department of Mechatronics Engineering, University of Firat University, Elazig, Turkey, (e-mail: resat.celikel@gmail.com).

(iD) https://orcid.org/0000-0002-9169-6466

AHMET GÜNDOĞDU, is with Department of Electrical Engineering University of Batman, Turkey, (e-mail: agundogdu23@gmail.com).

iD https://orcid.org/0000-0002-8333-3083

Manuscript received February 22, 2018; accepted April 02, 2021.

DOI: $\underline{10.17694 / \mathrm{bajece} .884815}$ algorithms are the Perturb and Observe (PO) and Incremental Conductance (INC) methods.

Many studies related to Maximum Power Point Tracking (MPPT) algorithms and their various derivatives have been conducted in the literature. The efficiencies of PO and INC methods were experimentally measured on the dynamic performance of a PV system according to the EN50530 standard, which is a European efficiency test standard. Accordingly, it was shown that as a result of tests conducted under the same conditions, the INC method had slightly higher efficiency than the PO Method [3]. In a literature study comparing conventional and modern MPPT methods, PO and INC methods were also examined in detail. In that study, by using a simulation study, it was shown that the power fluctuations occurring in the INC method were higher than in the PO method [4]. In addition to these studies, these two conventional methods have been the subject of many review articles [5-8]. In a study conducted using a low-cost microprocessor, comparisons of PO, INC, Fuzzy Logic Controller (FLC), Fractional Short-Circuit Current (FSCC), Fractional Open-Circuit Voltage (FOCV), and Neural Network (NN) MPPT methods were made. Also, the introduction of various low-cost microprocessors was carried out in that study [9]. In another study, on the other hand, by using the PO method together with various DC-DC converters, their performances were examined [10].

The conventional PO MPPT method has been modified using the variable-step PO method, and many studies have been conducted on this topic. In reference [11], the conventional PO MPPT method was reorganized as variablestep. In addition, the size of the variable step in the PO method was ensured by the PID controller. The parameters of the controller were calculated by using the genetic algorithm (GA). A power performance that had lower fluctuation was achieved in the proposed method. In reference [12], Hill Climb (HC), PO, INC, FLC, and the proposed Sliding Mode Controller (SMC) methods were compared under partial shading conditions. It was shown that the proposed method drew more power from the PV system and the drawn power had lower oscillation. A variable-step INC algorithm was 
introduced in reference [13]. By adding a driving technique with a voltage reference to this algorithm at start time, a power with lower oscillation was drawn both at startup and in steady state. By modifying the INC algorithm, Xu et al. [14] developed an effective MPPT method under both uniform radiation and partial shading conditions.

Devi et al. [15] modified the PO algorithm and developed an effective MPPT method that worked with high efficiency under fast-changing atmospheric conditions. In another study, a modified PO method that could work in two different modes was proposed. Compared to the conventional PO method, the proposed method was working with high efficiency under fastchanging atmospheric conditions [16]. In addition to these methods, many different modified MPPT algorithms have been developed. In the developed methods, the main goal is to achieve speed, high efficiency, and high adaptability to environmental conditions [17-20]. In another study, a new soft-MPPT algorithm that could be realized with low-level microprocessors and also used in conjunction with both $\mathrm{PO}$ and INC algorithms was proposed [21]. Both simulation and experimental study of the INC method used in conjunction with the CUK converter were carried out and compared [22].

The main goal of modified conventional MPPT algorithms and different control methods is to get the maximum possible efficiency from PV systems. There are many studies conducted for this purpose in the literature [23-26]. Conventional PO, modified PO and Learning Automata Optimization-supported hybrid PO methods were compared in reference [27]. Simulation studies of the proposed hybrid PO method were conducted for many different environmental conditions, and the success of the proposed method was shown. In another study, the superiority of the linear tangentsbased PO method over conventional methods was revealed by simulation studies [28]. A two-step PO method was developed to ensure that the power drawn from the PV system in steady state was higher [29]. The high performance of a new hybrid MPPT algorithm, which was created by combining the ABC (Artificial Bee Colony) optimization method and the PO method in a single-phase PV system, was shown under partial shading conditions $[30,31]$. The main purpose of adaptive MPPT algorithms is to ensure the improvement of dynamic performance in both the transient and steady state. Furthermore, using these algorithms, maximum power point monitoring is ensured with high efficiency under variable atmospheric conditions [32-35].

In addition to PO MPPT algorithms, INC MPPT methods and derivatives of these methods are also widely used in the literature [36]. A modified INC MPPT algorithm was compared with conventional PO and INC algorithms [37]. A variable-step INC MPPT algorithm was performed both as simulation and experimentally [38]. Optimization of parameters of a fractional order control-based INC MPPT algorithm was carried out [39]. An INC MPPT application was performed with a low-cost Arduino control card [40]. As an effective method under partial shading conditions, an Artificial Neural Network (ANN)-based INC MPPT method was proposed [41]. An evaluation study comparing the INC MPPT method with the PO method was conducted. A DC motor and pump were used as load [42]. By creating its model in the Proteus program of the PV panel, the INC MPPT algorithm was performed experimentally in a simulation environment [43]. By using a low-cost microcontroller and SEPIC converter, an INC MPPT application was carried out experimentally [44]. In a PV system where a CUK type DCDC converter was used, the success of the INC algorithm in which the step ratio was determined with FLC was tested [45]. A modified INC algorithm that could monitor the maximum power point under variable load and partial shading conditions was developed [46]. In another study, an INC MPPT algorithm that can work with high performance under fastchanging atmospheric conditions was introduced [47].

In addition to the conventional methods, solar monitoring systems using algorithms such as ANN and FLC, which work with higher performance but require high-level processors in practice, are also quite widespread [48-50]. In the application of these complex methods, Field Programmable Gate Arrays (FPGAs), whose use in control applications has increased in recent years, are used. Unlike the conventional processor structure, FPGA has a system making parallel processing. Therefore, it stands out with high processing speeds [51-53]. Apart from studies conducted with FPGA, the FPGA-in-theloop (FIL) feature has also been the subject of studies recently. FIL is used to test whether designed control methods or algorithms work with expected performance. The developed software has been designed so that it runs in FPGA. In reference [54], an estimation of the motor shaft angle was made via the ANN method by using resolver signals. The ANN structure was tested using the FIL feature. A new algorithm developed for energy measurement was run in the FIL environment [55]. An algorithm developed for fast detection of switching errors in a voltage-source inverter was first tested with FIL and then its experimental study was carried out [56]. The predictive current control algorithm developed for a grid-connected PV system was run in the FIL environment [57].

In this study, PO and INC MPPT algorithms were compared in terms of places they occupy in the microprocessor. For this purpose, the Altera Cyclone IV EP4CE115F29 FPGA chip on the Altera DE2-115 development platform was used. Primarily, these two algorithms, which were conventional, were reorganized so that they could work within FPGA. Moreover, the synthesizing 
process of the algorithms was carried out using the Quartus II program. Since the FPGA in-the-loop feature runs in the MATLAB/Simulink environment, the results obtained from running the PO and INC algorithms were graphically compared. As a result of the synthesizing, a comparison of the total areas covered by the algorithms was made. Thus, it was shown that MPPT algorithms could be tested without experimental study. In addition, information about the place that algorithms would occupy in the microprocessor was obtained. This study can be seen as a preliminary study for conducting studies in terms of simplifying the algorithms if it would be deemed necessary in the future.

\section{Photovoltaic System}

When creating a PV system, the desired power level can be achieved by connecting PV modules in series and parallel. In order for MPPT algorithms to be implemented, a DC-DC converter is connected to the output of the PV system. Thus, by setting the current and voltage drawn from the PV system, a maximum power is achieved in variable atmospheric conditions. The electrical equivalent circuit model of a PV cell can be obtained as shown in Figure $1[58,59]$.

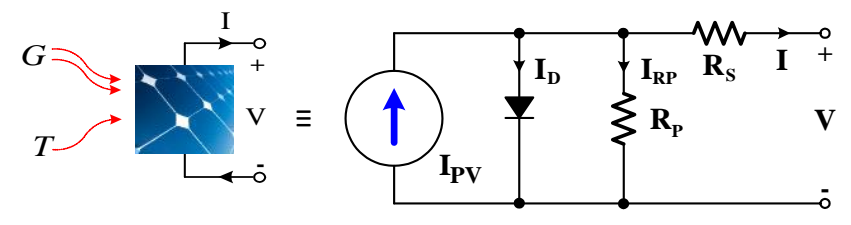

Fig.1. Electrical equivalent circuit model of a PV cell

The current produced by the PV cell here is given in Equations 1 and 2 .

$$
\begin{aligned}
& I=I_{P V}-I_{D}-I_{R_{P}} \\
& I=I_{P V}-I_{0}\left[\exp \left(\frac{V+R_{S} I}{a}\right)-1\right]-\frac{V+R_{S} I}{R_{P}}
\end{aligned}
$$

where $I_{0}$ is the leakage current of the diode. $a$ is an ideality factor and is given in Equation 3.

$$
a=\frac{N_{s} n k T}{q}
$$

where $N_{s}$ is the number of series-bound cells, $n$ is the diode ideality constant, $k$ is the Boltzmann constant $\left(1.3806503 \times 10^{-}\right.$ $\left.{ }^{23} \mathrm{~J} / \mathrm{K}\right), T$ is the cell temperature in Kelvin, and $q$ is the electron charge $\left(1.60217646 \times 10^{-19} \mathrm{C}\right)$. The cell current generated by the PV panel by the effect of light is given in Equation 4.

$$
I_{P V}=\left(I_{P V, n}+K_{I}\left(T-T_{n}\right)\right) \frac{G}{G_{n}}
$$

where $I_{P V, n}$ is the current generated at $25^{\circ} \mathrm{C}$ and $1000 \mathrm{~W} / \mathrm{m}^{2}, T$ is the current temperature (Kelvin), $T_{n}$ is the nominal temperature (Kelvin), $G$ is the radiation value on the panel surface $\left(\mathrm{W} / \mathrm{m}^{2}\right)$, and $G_{n}$ is the nominal radiation value $\left(\mathrm{W} / \mathrm{m}^{2}\right)$. The saturation current $\left(I_{0}\right)$ of the diode is given in Equation 5.

$$
I_{0}=\frac{I_{S C, n}+K_{I}\left(T-T_{n}\right)}{\exp \left(\frac{V_{O C, n}+K_{V}\left(T-T_{n}\right)}{a}\right)-1}
$$

where $I_{S C, n}$ is the rated short-circuit current, $V_{O C, n}$ is the rated open circuit voltage, $K_{I}$ is the current coefficient, and $K_{V}$ is the voltage coefficient.

In this study, a PV power system with $10 \mathrm{~kW}$ power was created using Trina TSM-250PA05.08 model PV panels in MATLAB/Simulink environment. Figure 2 shows currentvoltage graph of the panel under standard test conditions-STC.

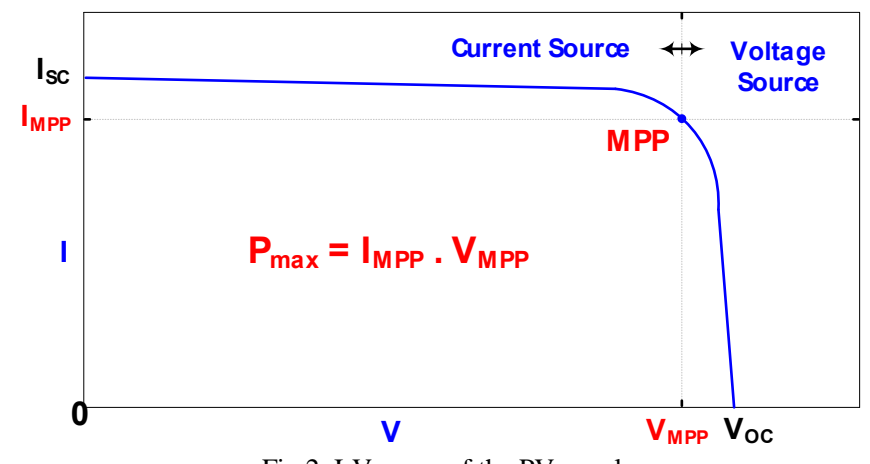

Fig.2. I-V curve of the PV panel

\section{A. Boost Converter}

The circuit structure of an ideal boost converter is seen in Figure 3. For the case where the switch is off, the $V_{s}$ voltage source is serially connected to the $L$ coil and the tension formula can be written as in Equations 6 and 7.

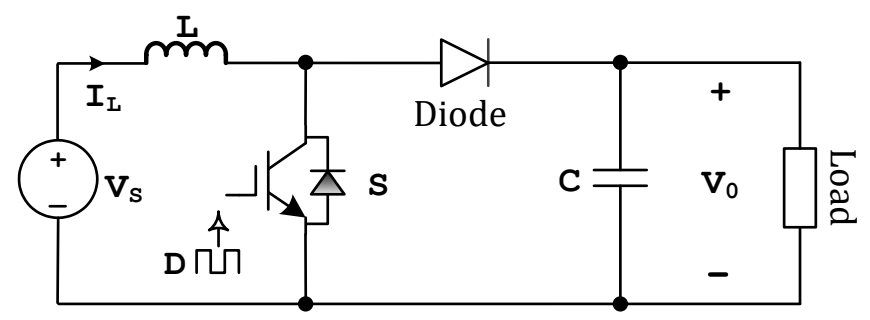

Fig.3. Boost converter 
BALKAN JOURNAL OF ELECTRICAL \& COMPUTER ENGINEERING, $\quad$ Vol. 9, No. 2, April 2021

$$
\begin{aligned}
& V_{s}(t)=L \frac{d_{I_{L}}}{d t} \\
& \frac{\Delta_{I_{L}}}{\Delta t}=\frac{V_{s}}{L}
\end{aligned}
$$

The time of the switch to remain in transmission $(\Delta t)$ can be written as $D T_{s}$, and the time to remain in cutoff can be written as $(1-D) T_{s}$. Here, while $D$ refers to the task period of the switch, $T_{s}$ refers to the switching period. Accordingly, the expression of the current during the transmission time of the switch is seen in Equation 8, and the expression of the current during the cutoff time of the Switch is seen in Equation 9.

$$
\begin{aligned}
& \Delta_{I_{L}}=\frac{V_{s}}{L} D T_{s} \\
& \Delta_{I_{L}}=\frac{V_{s}-V_{0}}{L}(1-D) T_{s}
\end{aligned}
$$

The sum of the change in current seen in Equations 8 and 9 will be zero within one period. When this expression is written, the change of output voltage depending on the task period is given in Equation 10.

$$
V_{0}=\frac{V_{s}}{1-D}
$$

\section{PO AND INC MPPT METHODS}

In the conventional PO MPPT method, voltage and power changes in each step are measured. Taking into account the change in power and voltage, the switching task period of the boost converter is changed in a way that the voltage will be increased and decreased at the magnitude of $\Delta V_{\text {ss. }}$ The flow diagram for the application of the PO method is shown in Figure 4(a).

The conventional INC MPPT method is created by observing the peak of the power-voltage curve of the PV system (i.e. by finding the point where the slope is zero, and also observing the current-voltage curve). The flow diagram for the implementation of the INC method is shown in Figure 4(b). While the maximum output power of the PV system is given in Equation 11, the restatement of power by using differential equations is given in Equations 12 and 13.

$$
P_{M P P}=V_{M P P} x I_{M P P}
$$

$$
\begin{aligned}
& \frac{d P}{d V}=I+V \frac{d I}{d V}=0 \\
& \frac{d I}{d V} \cong \frac{\Delta I}{\Delta V}=-\frac{I_{M P P}}{V_{M P P}}
\end{aligned}
$$

The three applied derivatives associated with catching the MPP point are seen in Equation 14.

$$
\begin{cases}\frac{d P}{d V}=0, & \frac{\Delta I}{\Delta V}=-\frac{I}{V} \\ \frac{d P}{d V}>0, & \frac{\Delta I}{\Delta V}>-\frac{I}{V} \\ \frac{d P}{d V}<0, & \frac{\Delta I}{\Delta V}<-\frac{I}{V}\end{cases}
$$

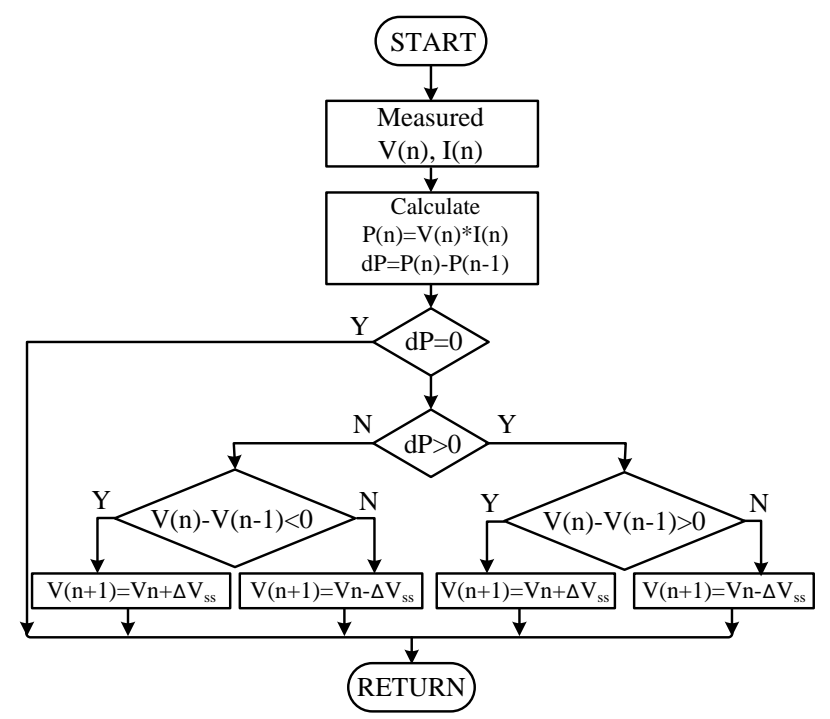

a)

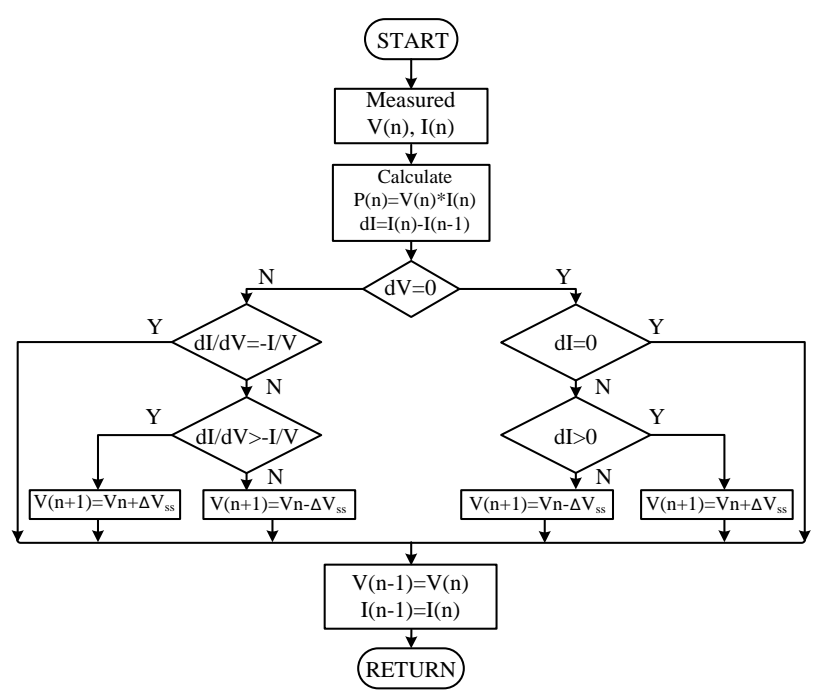

b)

Fig.4. Flow diagrams for a) PO MPPT method and b) INC MPPT method 


\section{FPGA IN-THE-LOOP (FIL) AND RESULTS}

FIL is performed by using the Altera FPGA, which operates in line with MATLAB/Simulink. The FIL feature is used to test whether a control algorithm developed in the MATLAB/Simulink environment or a different model works or not. In this way, before the installation of large-cost systems, the accuracy of the algorithms and models that will work on the system is ensured. In order for the FIL feature to be able to operate, the algorithm to be tested must be synthesized first. Therefore, it is required that the algorithm to be tested is designed in a way that it can work within FPGA. In this study, the areas covered by PO and INC algorithms, which are among the conventional MPPT algorithms, in an FPGA and their performances were compared. In this way, it was shown that the determination of the areas covered by MPPT algorithms in a microprocessor and analysis of their performances can be made with the FIL feature. Because the software would run in FPGA, the sample time of the simulation was set to $20 \mathrm{~ns}$, which was the operating frequency of the used FPGA. Since the switching frequency of the Boost converter was $20 \mathrm{kHz}$ in the simulation study, the measurement time of current and voltage was set to $50 \mu \mathrm{s}$. In addition, in both algorithms, time settings were made in accordance with the order of current, voltage, and power changes in the flow diagram and the sampling time. Figure 5(a) and 5(b) show the sampling times of the MATLAB/Simulink simulation of PO and INC methods, respectively. These sampling times were set in a way that they would run in FPGA.

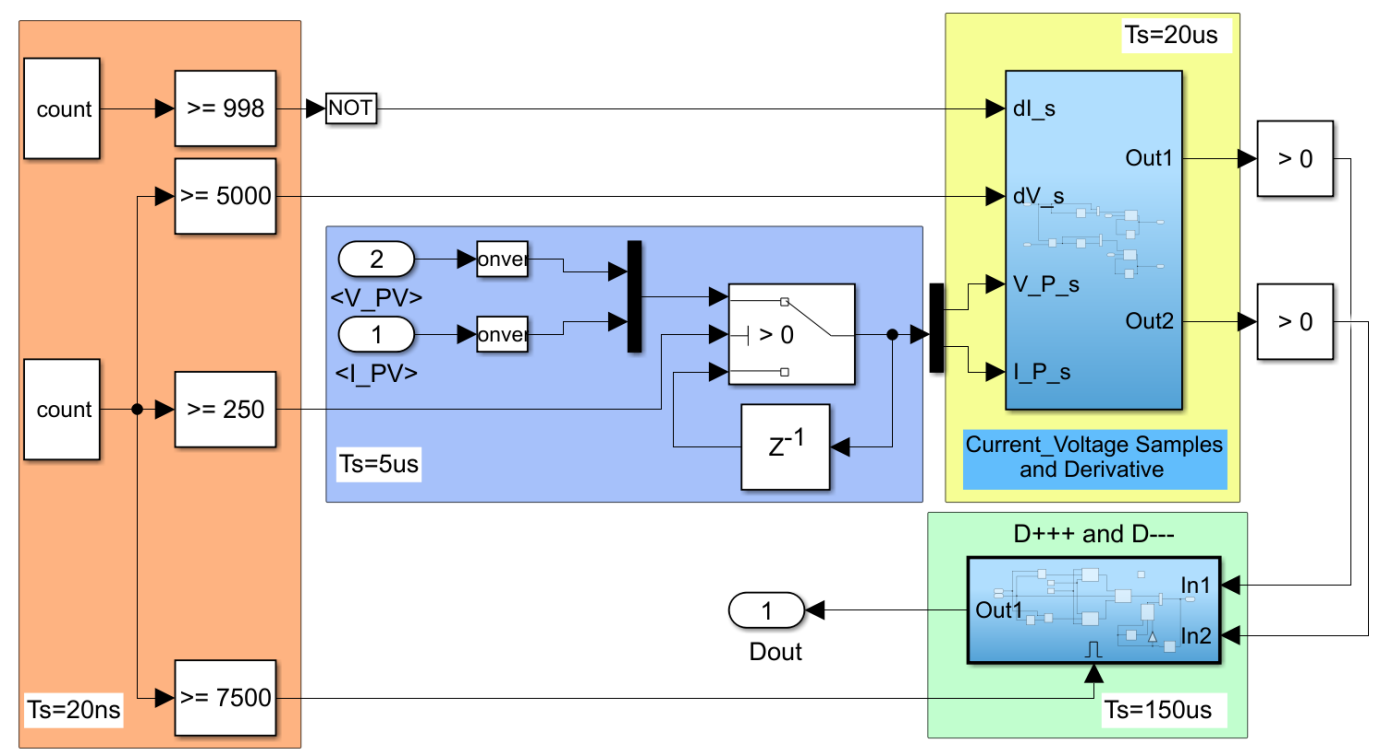

a)

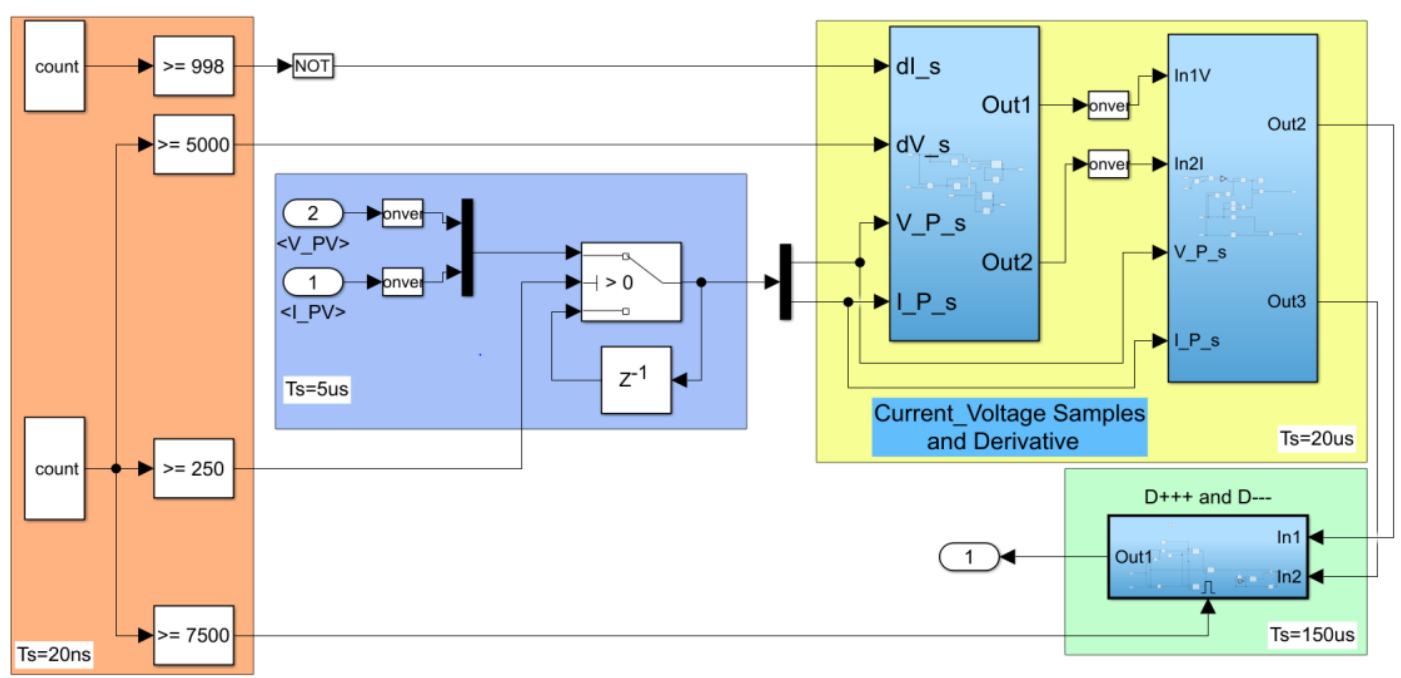

b)

Fig.5. MATLAB/Simulink blocks synthesized by FPGA: a) PO method b) INC method 
In algorithms running in FPGA, operations do not work in double format. Therefore, inputs, outputs and operations were reorganized in fixed point or integer formats. The
MATLAB/Simulink simulation study, which also includes the FIL block, is seen in Figure 6.

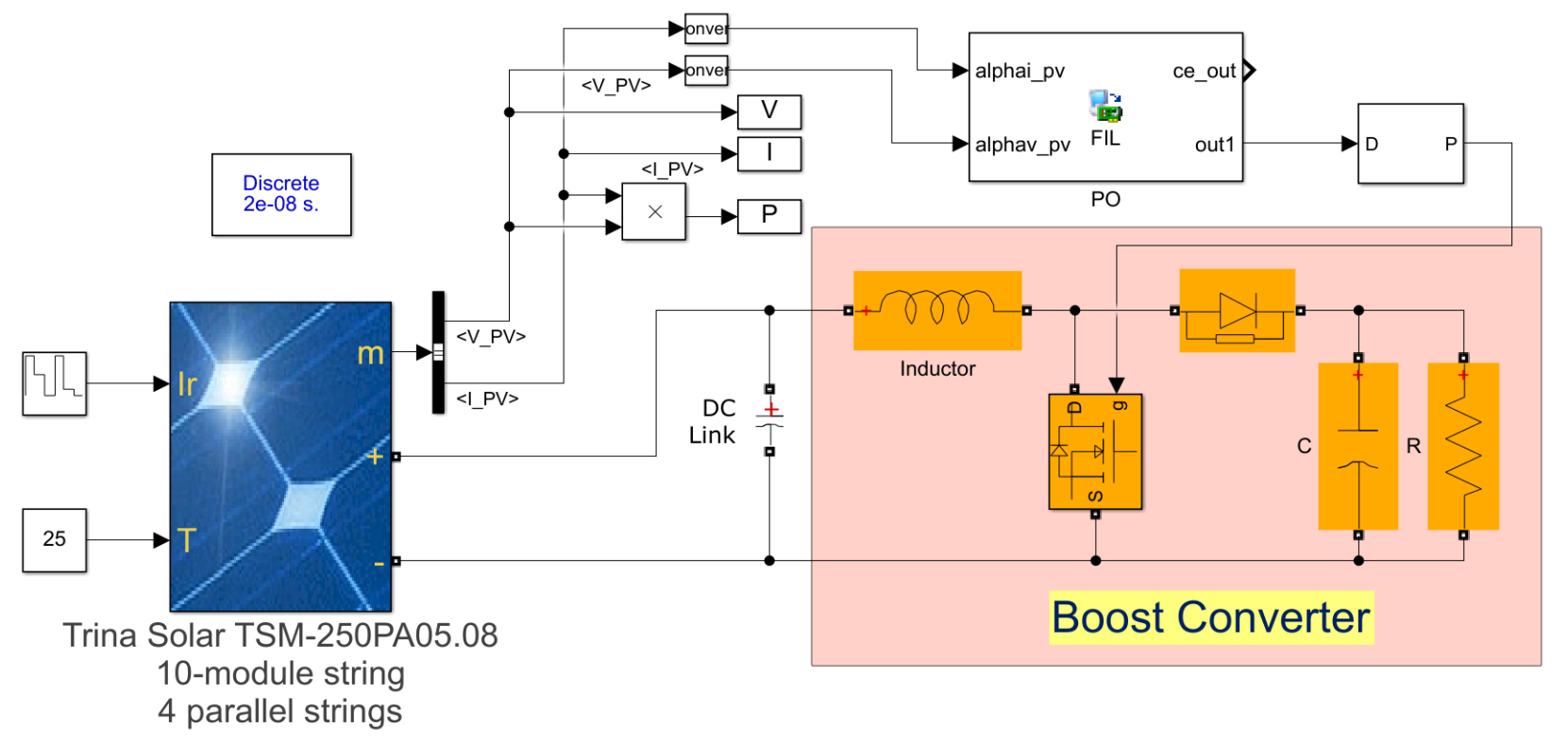

Fig.6. MATLAB/Simulink simulation including FIL block

The simulation study was carried out using MATLAB/Simulink and Altera DE2-115 Development Board. The FPGA used on the board is a product of Cyclone IV EP4CE115F29. Both algorithms were run together with FPGA by using the FIL block under the same conditions. Figure 7 shows the power obtained by PO and INC method at different radiation values $\left(1000-700-400 \mathrm{~W} / \mathrm{m}^{2}\right)$ under a temperature of $25^{\circ} \mathrm{C}$. Figure 8 shows graphs of current and voltage generated at the same radiation values.

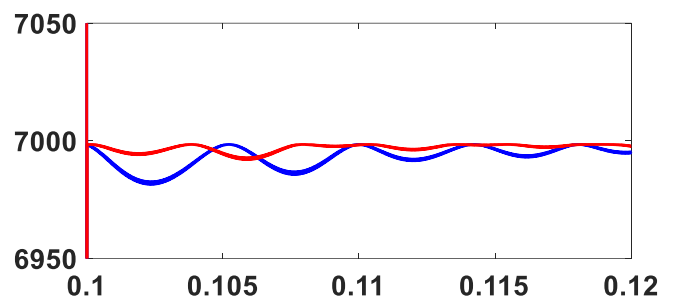

(b)

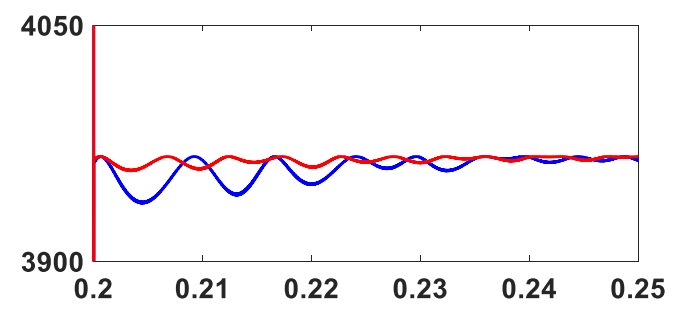

t (s)

Fig.7. Power obtained by $\mathrm{PO}$ and $\mathrm{INC}$ method at $25^{\circ} \mathrm{C}$; a) at different radiation values b)at $1000 \mathrm{~W} / \mathrm{m}^{2}$ radiation value c) at $700 \mathrm{~W} / \mathrm{m}^{2}$ radiation value d) at 400 $\mathrm{W} / \mathrm{m}^{2}$ radiation value 

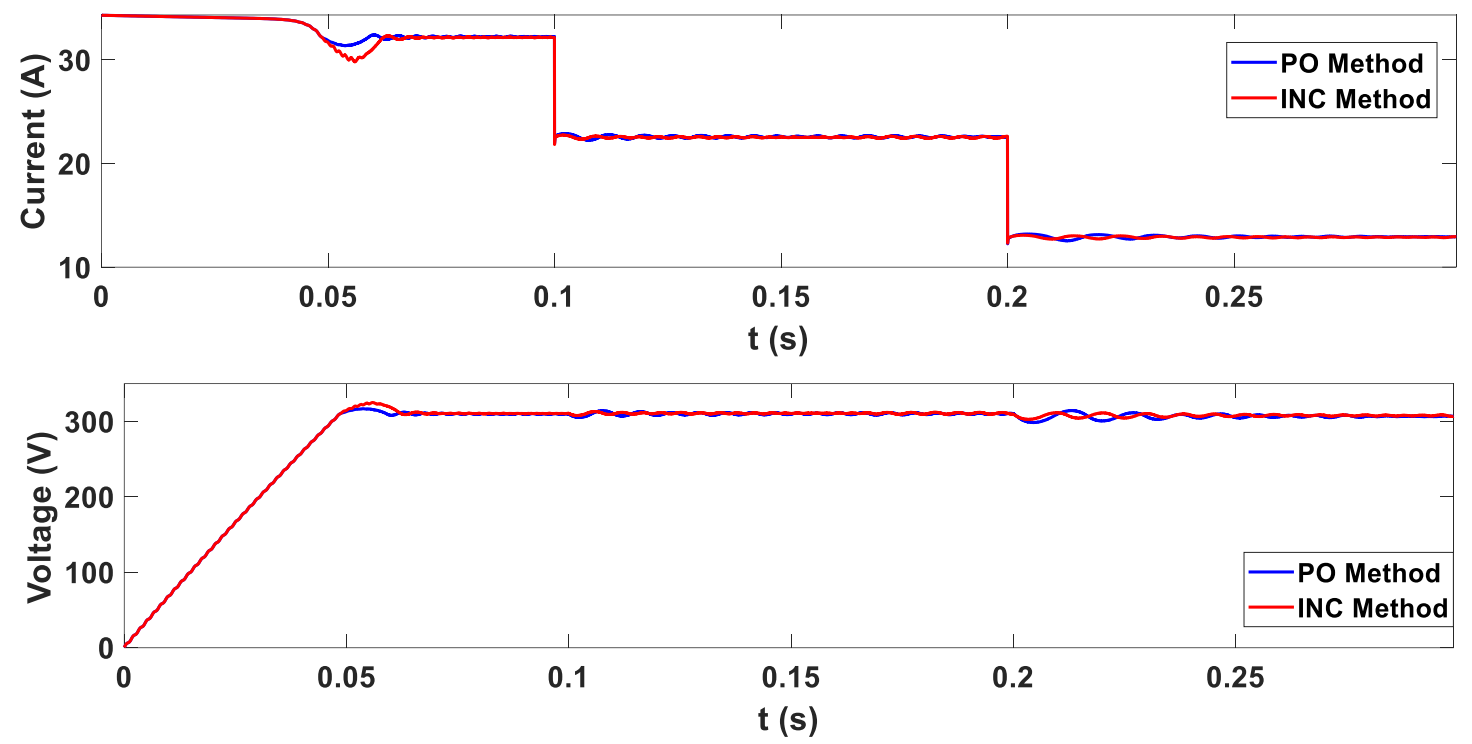

Fig.8. Current and voltage obtained by PO and INC methods under the same atmospheric conditions

\begin{tabular}{||} 
Flow Summary \\
\hline Flow Status \\
Quartus II Version & Successful - Sun Jan 10 20:13:05 2021 \\
Revision Name & 10.0 Build $21806 / 27 / 2010$ S] Web Edition \\
Top-level Entity Name & PO \\
Family & Subsystem1 \\
Device & Cyclone IV E \\
Timing Models & EP4CE115F29C7 \\
Met timing requirements & Final \\
Total logic elements & N/A \\
Total combinational functions & $456 / 114,480(<1 \%)$ \\
Dedicated logic registers & $456 / 114,480(<1 \%)$ \\
Total registers & $195 / 114,480(<1 \%)$ \\
Total pins & 195 \\
\hline Total virtual pins & $84 / 529(16 \%)$ \\
Total memory bits & 0 \\
Embedded Multiplier 9-bit elements & $0 / 3,981,312(0 \%)$ \\
Total PLLs & $0 / 432(2 \%)$ \\
&
\end{tabular}

a)

\begin{tabular}{|c|c|}
\hline \multicolumn{2}{|l|}{ Flow Summary } \\
\hline Flow Status & Successful - Sun Jan 10 20:17:06 2021 \\
\hline Quartus II Version & 10.0 Build $21806 / 27 / 2010 \mathrm{SJ}$ Web Edition \\
\hline Revision Name & INC \\
\hline Top-level Entity Name & Subsystem 1 \\
\hline Family & Cyclone IV E \\
\hline Device & EP4CE115F29C7 \\
\hline Timing Models & Final \\
\hline Met timing requirements & N/A \\
\hline Total logic elements & $5,125 / 114,480(4 \%)$ \\
\hline Total combinational functions & $5,125 / 114,480(4 \%)$ \\
\hline Dedicated logic registers & $195 / 114,480(<1 \%)$ \\
\hline Total registers & 195 \\
\hline Total pins & $84 / 529(16 \%)$ \\
\hline Total virtual pins & 0 \\
\hline Total memory bits & $0 / 3,981,312(0 \%)$ \\
\hline Embedded Multiplier 9-bit elements & $24 / 532(5 \%)$ \\
\hline Total PLLs & $0 / 4(0 \%)$ \\
\hline
\end{tabular}

b)

Fig.9. Flow summary of synthesis with FPGA: a) PO algorithm b) INC algorithm

When Figure 7 is examined, it is seen that at the first starting time, the oscillation in the PO method was less when it caught the MPP point. At $700 \mathrm{~W} / \mathrm{m}^{2}$ and $400 \mathrm{~W} / \mathrm{m}^{2}$ radiation values, the power fluctuation in the $\mathrm{PO}$ method was more compared to the INC method. However, in steady state, these power oscillations were very close to each other. In order for that the power oscillations were not too much at the first starting time, a task period locking method was used to fix the task period to 0.05 if the task period went negative. Accordingly, there were no major differences in the application of $\mathrm{PO}$ and INC methods. In order to understand the space these two algorithms, which have superiority over each other in various regions, occupy in the microprocessor, a synthesis process was performed using the Quartus II program. Figure 9 shows the results of the synthesis process.

Figure 9(a) shows a summary of the flow occurring as a result of synthesizing the PO method, while Figure 9(b) shows a summary of the flow occurring as a result of synthesizing the INC method. The synthesis result shows that the INC algorithm takes up more space in FPGA than the PO algorithm. Accordingly, it is clearly seen that the processing load is greater in the implementation of the INC algorithm. In terms of tracking the MPP point, it has been observed that these algorithms, which have different advantages over each other in different regions in transient state, have too little superiority over each other in steady state. The fact that the processing load in the INC algorithm is excessive is due to the division operations contained in the algorithm. At the end of the synthesis process, it was seen that the division process was a significant processing load for FPGAs.

\section{CONCLUSIONS}

PO and INC, which are among the conventional MPPT algorithms, are two of the most commonly used methods. Comparisons of these algorithms and their various derivatives are quite common in the literature. FIL is a feature used to test algorithms that work and are designed in the 
MATLAB/Simulink environment together with Altera FPGA. In this study, PO and INC MPPT algorithms were tested in the MATLAB/Simulink environment by using the FIL feature. These algorithms prepared in MATLAB/Simulink environment with Altera DE2-115 development platform, working synchronously. In order for algorithms to be able to run on a real system, time settings were made. In the next stage, to examine the areas covered by PO and INC methods in FPGA, the synthesis process was carried out using the Quartus II program. As a result of the FIL simulation performed at constant temperature and different radiation values, it was observed that the PO and INC methods had little superiority over each other in different regions. As a result of the synthesis process, on the other hand, it was shown that the PO method takes up less space in FPGA than the INC method. Accordingly, thanks to graphics obtained by FIL application and flow summary obtained as a result of synthesis process, it was clearly seen that in terms of ease of application, the PO method was superior to the INC method.

\section{REFERENCES}

[1] C. Larbes, S.M.A. Cheikh, T. Obeidi, A. Zerguerras. "Genetic algorithms optimized fuzzy logic control for the maximum power point tracking in photovoltaic system." Renew Energy. Vol. 34, 2009, pp 2093-2100.

[2] R. Celikel, A. Gundogdu. "System identification-based MPPT algorithm for PV systems under variable atmosphere conditions using current sensorless approach." International Transactions on Electrical Energy Systems, 2020, e12433.

[3] K. Ishaque, Z. Salam, G. Lauss. "The performance of perturb and observe and incremental conductance maximum power point tracking method under dynamic weather conditions." Applied Energy, vol. 119, 2014, pp 228-236.

[4] A. Gupta, Y. K. Chauhan, R. K. Pachauri. "A comparative investigation of maximum power point tracking methods for solar PV system." Solar Energy, vol. 136, 2016, pp 236-253.

[5] X. Li, H. Wen, Y. Hu, Y. Du, Y. Yang. "A comparative study on photovoltaic MPPT algorithms under EN50530 dynamic test procedure." IEEE Transactions on Power Electronics, vol. 36. 4, 2020, pp 4153-4168.

[6] A. R. Reisi, M. H. Moradi, S. Jamasb. "Classification and comparison of maximum power point tracking techniques for photovoltaic system. A review." Renewable and Sustainable Energy Reviews, vol. 19, 2013, pp 433-443.

[7] M. A. Husain, A. Tariq, S. Hameed, M. S. B. Arif, A. Jain. "Comparative assessment of maximum power point tracking procedures for photovoltaic systems." Green Energy \& Environment, vol. 2. 1, 2017, pp 5-17.

[8] H. Bounechba, A. Bouzid, K. Nabti, H. Benalla. "Comparison of perturb $\&$ observe and fuzzy logic in maximum power point tracker for PV systems." Energy Procedia, vol. 50. 1, 2014, pp 677-684.

[9] S. Motahhir, A. El Hammoumi, A. El Ghzizal. "The most used MPPT algorithms: Review and the suitable low-cost embedded board for each algorithm.” Journal of Cleaner Production, vol. 246, 2020, 118983.

[10] M. E. Başoğlu. "Analyzes of Flyback DC-DC Converter for Submodule Level Maximum Power Point Tracking in Off-grid Photovoltaic Systems." Balkan Journal of Electrical and Computer Engineering, vol. 7. 3, 2019, pp 269-275.
[11] A., Harrag, S. Messalti. "Variable step size modified P\&O MPPT algorithm using GA-based hybrid offline/online PID controller." Renewable and Sustainable Energy Reviews, vol. 49, 2015, pp 12471260

[12] Z. M. Ali, N. V. Quynh, S. Dadfar, H. Nakamura. "Variable step size perturb and observe MPPT controller by applying $\theta$-modified krill herd algorithm-sliding mode controller under partially shaded conditions." Journal of Cleaner Production, vol. 271, 2020, 122243.

[13] F. Liu, S. Duan, F. Liu, B. Liu, Y. Kang. "A variable step size INC MPPT method for PV systems." IEEE Transactions on Industrial Electronics, vol. 55. 7, 2008, pp 2622-2628.

[14] L. Xu, R. Cheng, J. Yang. "A Modified INC Method for PV String Under Uniform Irradiance and Partially Shaded Conditions." IEEE Access, vol. 8, 2020, pp 131340-131351.

[15] V. K. Devi, K. Premkumar, A. B. Beevi, S. Ramaiyer. "A modified Perturb \& Observe MPPT technique to tackle steady state and rapidly varying atmospheric conditions." Solar Energy, vol. 157, 2017, pp 419426.

[16] A. Ghamrawi, J. P. Gaubert, D. Mehdi. "A new dual-mode maximum power point tracking algorithm based on the Perturb and Observe algorithm used on solar energy system." Solar Energy, vol. 174, 2018, pp 508-514.

[17] S. C. Wang, H. Y. Pai, G. J. Chen, Y. H. Liu. "A Fast and Efficient Maximum Power Tracking Combining Simplified State Estimation With Adaptive Perturb and Observe." IEEE Access, vol. 8, 2020, pp 155319155328.

[18] R. Balasankar, G. T. Arasu, J. C. M. Raj. "A global MPPT technique invoking partitioned estimation and strategic deployment of $\mathrm{P} \& \mathrm{O}$ to tackle partial shading conditions." Solar Energy, vol. 143, 2017, pp 7385.

[19] S. Mohanty, B. Subudhi, P. K. Ray. "A grey wolf-assisted perturb \& observe MPPT algorithm for a PV system." IEEE Transactions on Energy Conversion, vol. 32. 1, 2016, pp 340-347.

[20] S. Lyden, H. Galligan, M. E. Haque. "A Hybrid Simulated Annealing and Perturb and Observe Maximum Power Point Tracking Method." IEEE Systems Journal, 2020, DOI: 10.1109/JSYST.2020.3021379.

[21] S. Bhattacharyya, D. S. K. Patnam, S. Samanta, S. Mishra. "Steady Output and Fast Tracking MPPT (SOFT MPPT) for P\&O and InC Algorithms." IEEE Transactions on Sustainable Energy, vol. 12. 1, 2021, pp 293-302.

[22] A. Safari, S. Mekhilef. "Simulation and hardware implementation of incremental conductance MPPT with direct control method using cuk converter." IEEE Transactions on Industrial Electronics, vol. 58. 4, 2010, pp 1154-1161.

[23] E. Bianconi, J. Calvente, R. Giral, E. Mamarelis, G. Petrone, C. A. Ramos-Paja, M. Vitelli. "Perturb and observe MPPT algorithm with a current controller based on the sliding mode." International Journal of Electrical Power \& Energy Systems, vol. 44. 1, 2013, pp 346-356.

[24] D. Sera, L. Mathe, T. Kerekes, S. V. Spataru, R. Teodorescu. "On the perturb-and-observe and incremental conductance MPPT methods for PV systems." IEEE Journal of Photovoltaics, vol. 3. 3, 2013, pp 10701078

[25] K. Yan, Y. Du, Z. Ren. "MPPT perturbation optimization of photovoltaic power systems based on solar irradiance data classification." IEEE Transactions on Sustainable Energy, vol. 10. 2, 2018, pp 514-521.

[26] V. Kumar, M. Singh. "Derated Mode of Power Generation in PV System Using Modified Perturb and Observe MPPT Algorithm." Journal of Modern Power Systems and Clean Energy, 2020, DOI: 10.35833/MPCE.2019.000258

[27] S. S. Mohammed, D. Devaraj, T. I. Ahamed. "A novel hybrid maximum power point tracking technique using perturb \& observe algorithm and learning automata for solar PV system.” Energy, vol. 112, 2016, pp 1096-1106. 
[28] V. R. Kota, M. N. Bhukya. "A novel linear tangents-based P\&O scheme for MPPT of a PV system." Renewable and Sustainable Energy Reviews, vol. 71, 2017, pp 257-267.

[29] E. Mamarelis, G. Petrone, G. Spagnuolo. "A two-steps algorithm improving the P\&O steady state MPPT efficiency." Applied Energy, vol. 113, 2014, pp 414-421.

[30] D. Pilakkat, S. Kanthalakshmi. "Single phase PV system operating under Partially Shaded Conditions with ABC-PO as MPPT algorithm for grid connected applications.” Energy Reports, vol. 6, 2020, pp 1910-1921.

[31] D. Pilakkat, S. Kanthalakshmi. "An improved P\&O algorithm integrated with artificial bee colony for photovoltaic systems under partial shading conditions." Solar Energy, vol. 178, 2019, pp 37-47.

[32] Y. Yang, H. Wen. "Adaptive perturb and observe maximum power point tracking with current predictive and decoupled power control for gridconnected photovoltaic inverters." Journal of Modern Power Systems and Clean Energy, vol. 7. 2, 2019, pp 422-432.

[33] Y. Yang, F. P. Zhao. "Adaptive perturb and observe MPPT technique for grid-connected photovoltaic inverters." Procedia Engineering, vol. 23, 2011, pp 468-473.

[34] J. Ahmed, Z. Salam. "An enhanced adaptive P\&O MPPT for fast and efficient tracking under varying environmental conditions." IEEE Transactions on Sustainable Energy, vol. 9. 3, 2018, pp 1487-1496.

[35] R. Alik, A. Jusoh. "An enhanced P\&O checking algorithm MPPT for high tracking efficiency of partially shaded PV module." Solar Energy, vol. 163, 2018, pp 570-580.

[36] J. L. Díaz-Barnabé, A. Morales-Acevedo. "Experimental study of the equivalence of the Adaptive Incremental Conductance (AIC) and the Adaptive Perturb and Observe (APO) algorithms for PV systems maximum power tracking." IEEE Latin America Transactions, vol. 17. 8, 2019, pp 1237-1243.

[37] S. Motahhir, A. El Hammoumi, A. El Ghzizal. "Photovoltaic system with quantitative comparative between an improved MPPT and existing INC and $\mathrm{P} \& \mathrm{O}$ methods under fast varying of solar irradiation." Energy Reports, vol. 4, 2018, pp 341-350.

[38] A. Loukriz, M. Haddadi, S. Messalti. "Simulation and experimental design of a new advanced variable step size Incremental Conductance MPPT algorithm for PV systems." ISA transactions, vol. 62, 2016, pp 30-38.

[39] M. Al-Dhaifallah, A. M. Nassef, H. Rezk, K. S. Nisar. "Optimal parameter design of fractional order control-based INC-MPPT for PV system." Solar Energy, vol. 159, 2018, 650-664.

[40] O. Oussalem, M. Kourchi, A. Rachdy, M. Ajaamoum, H. Idadoub, S. Jenkal. "A low cost controller of PV system based on Arduino board and INC algorithm.” Materials Today: Proceedings, vol. 24, 2020, pp 104109.

[41] K. Punitha, D. Devaraj, S. Sakthivel. "Artificial neural network based modified incremental conductance algorithm for maximum power point tracking in photovoltaic system under partial shading conditions." Energy, vol. 62, 2013, pp 330-340.

[42] M. A. Elgendy, B. Zahawi, D. J. Atkinson. "Assessment of the incremental conductance maximum power point tracking algorithm." IEEE Transactions on Sustainable Energy, vol. 4. 1, 2012, pp 108-117.

[43] S. Motahhir, A. Chalh, A. El Ghzizal, A. Derouich. "Development of a low-cost PV system using an improved INC algorithm and a PV panel Proteus model." Journal of Cleaner Production, vol. 204, 2018, pp 355365.

[44] S. Necaibia, M. S. Kelaiaia, H. Labar, A. Necaibia, E. D. Castronuovo. "Enhanced auto-scaling incremental conductance MPPT method, implemented on low-cost microcontroller and SEPIC converter." Solar Energy, vol. 180, 2019, pp 152-168.

[45] T. Radjai, L. Rahmani, S. Mekhilef, J. P. Gaubert. "Implementation of a modified incremental conductance MPPT algorithm with direct control based on a fuzzy duty cycle change estimator using dSPACE." Solar Energy, vol. 110, 2014, pp 325-337.
[46] K. S. Tey, S. Mekhilef. "Modified incremental conductance algorithm for photovoltaic system under partial shading conditions and load variation." IEEE Transactions on Industrial Electronics, vol. 61. 10, 2014, pp 5384-5392.

[47] K. S. Tey, S. Mekhilef. "Modified incremental conductance MPPT algorithm to mitigate inaccurate responses under fast-changing solar irradiation level." Solar Energy, vol. 101, 2014, pp 333-342.

[48] R. Çelikel, A. Gündoğdu. "ANN-Based MPPT Algorithm for Photovoltaic Systems." Turkish Journal of Science and Technology, vol. 15. 2, 2020, pp 101-110.

[49] F. Kentli, M. Yilmaz. "Mathematical modelling of two-axis photovoltaic system with improved efficiency." Elektronika Ir Elektrotechnika, vol. 21. 4, 2015, pp 40-43.

[50] A. Youssef, M. El Telbany, A. Zekry. "Reconfigurable generic FPGA implementation of fuzzy logic controller for MPPT of PV systems." Renewable and Sustainable Energy Reviews, vol. 82, 2018, pp 13131319.

[51] A. Senthilvel, K. N. Vijeyakumar, B. Vinothkumar. FPGA Based Implementation of MPPT Algorithms for Photovoltaic System under Partial Shading Conditions. Microprocessors and Microsystems, 2020, 103011.

[52] A. Messai, A. Mellit, A. M. Pavan, A. Guessoum, H. Mekki. "FPGAbased implementation of a fuzzy controller (MPPT) for photovoltaic module." Energy Conversion and Management, vol. 52. 7, 2011, pp 2695-2704

[53] A. Mellit, H. Rezzouk, A. Messai, B. Medjahed. "FPGA-based real time implementation of MPPT-controller for photovoltaic systems." Renewable Energy, vol. 36. 5, 2011, 1652-1661.

[54] R. Celikel. "ANN based angle tracking technique for shaft resolver." "Measurement, vol. 148, 2019, 106910.

[55] S. Jaiswal, M. S. Ballal. "FDST-based PQ event detection and energy metering implementation on FPGA-in-the-loop and NI-LabVIEW." IET Science, Measurement \& Technology, vol. 11. 4, 2017, pp 453463.

[56] S. Karimi, P. Poure, S. Saadate. "Fast power switch failure detection for fault tolerant voltage source inverters using FPGA." IET Power Electronics, vol. 2. 4, 2009, pp 346-354.

[57] M. Morales-Caporal, J. Rangel-Magdaleno, H. Peregrina-Barreto, R. Morales-Caporal. "FPGA-in-the-loop simulation of a grid-connected photovoltaic system by using a predictive control." Electrical Engineering, vol. 100. 3, 2018, pp 1327-1337.

[58] E. Deniz. "ANN-based MPPT algorithm for solar PMSM drive system fed by direct-connected PV array." Neural Computing and Applications, vol. 28. 10, 2017, pp 3061-3072.

[59] O. Aydogmus. "Design of a solar motor drive system fed by a directconnected photovoltaic array." Advances in Electrical and Computer Engineering, vol. 12. 3, 2012, pp 53-58.

\section{BIOGRAPHIES}

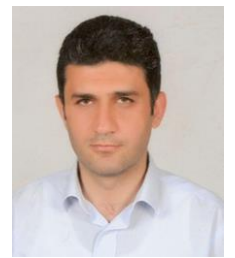

REŞAT ÇELIKKEL was born in 1980. He received B.S, M.S and PhD degrees from Firat University, Elazığ, Turkey. He has been working as an Assist. Prof. Dr. at Batman University. His current interests are electric machines, flywheel energy storage, FPGA, renewable energy.

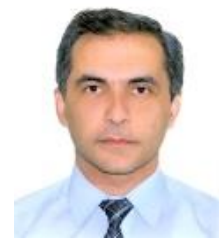

AHMET GÜNDOĞDU Elazığ in 1974. He received the B.S. and M.S. degrees in electrical teaching from the University of Firat, Elazı $\breve{g}$, in 2004 and the Ph.D. degree in electrical engineering from Firat University, Elazı ğ, in 2012. 